\title{
Synthesis of Well-Defined Pyrrolidone-Based Homopolymers and Stimulus-Responsive Diblock Copolymers via RAFT Aqueous Solution Polymerization of 2-( $\mathrm{N}$-Acryloyloxy)ethylpyrrolidone
}

\author{
O. J. Deane, ${ }^{\dagger}$ J. R. Lovett, ${ }^{\dagger}$ O. M. Musa, ${ }^{\ddagger}$ A. Fernyhough, ${ }^{\S}$ and S. P. Armes ${ }^{* \dagger}{ }^{\dagger}$ \\ ${ }^{\dagger}$ Dainton Building, Department of Chemistry, University of Sheffield, Brook Hill, Sheffield, South Yorkshire S3 7HF, U.K. \\ *Ashland Specialty Ingredients, 1005 US 202/206, Bridgewater, New Jersey 08807, United States \\ ${ }^{\S}$ Ashland Specialty Ingredients, Listers Mills, Heaton Road, Bradford, West Yorkshire BD9 4SH, U.K.
}

Supporting Information

\begin{abstract}
Poly}(N$-vinylpyrrolidone) (PNVP) is a well-known, highly polar, nonionic water-soluble polymer. However, $\mathrm{N}$-vinylpyrrolidone (NVP) usually exhibits strongly non-ideal behavior when copolymerized with methacrylic or styrenic monomers. Moreover, NVP is not particularly well-controlled under living radical polymerization conditions. For these reasons, alternative pyrrolidone-based monomers have been investigated. For example, the reversible addition-fragmentation chain transfer (RAFT) polymerization of 2-( $N$-methacryloyloxy)ethylpyrrolidone

Novel Stimulus-Responsive Diblock Copolymers Based on NAEP (NMEP) has been recently investigated using various polymerization formulations. However, PNMEP homopolymers are significantly less hydrophilic than PNVP and exhibit inverse temperature solubility in aqueous solution. In the present work, we studied the RAFT aqueous solution polymerization of 2-( $N$-acryloyloxy)ethylpyrrolidone (NAEP) using either AIBN at $70{ }^{\circ} \mathrm{C}$ or a low-temperature redox initiator at $30{ }^{\circ} \mathrm{C}$. PNAEP homopolymers are obtained in high yield $(>99 \%)$ with good control $\left(M_{\mathrm{w}} / M_{\mathrm{n}}<1.20\right)$ for target degrees of polymerization (DP) of up to 400 using the latter initiator, which produced relatively fast rates of polymerization. However, targeting DPs above 400 led to lower NAEP conversions and broader molecular weight distributions. 2-Hydroxyethyl acrylate (HEA) and oligo(ethylene glycol) methyl ether acrylate (OEGA) were chain-extended using a $\operatorname{PNAEP}_{x}$ macro-CTA via RAFT aqueous solution polymerization, yielding double-hydrophilic acrylic diblock copolymers with high conversions $(>99 \%)$ and good control $\left(M_{\mathrm{w}} / M_{\mathrm{n}}<1.31\right)$. In addition, a PNAEP ${ }_{95}$ macro-CTA was chainextended via RAFT aqueous solution polymerization of $\mathrm{N}$-isopropylacrylamide (NIPAM) at $22{ }^{\circ} \mathrm{C}$. Dynamic light scattering (DLS) analysis indicated that heating above the lower critical solution temperature of PNIPAM led to so-called "anomalous micellization" at $35{ }^{\circ} \mathrm{C}$ and the formation of near-monodisperse spherical micelles at $40{ }^{\circ} \mathrm{C}$. Finally, 2-(diethylamino)ethyl methacrylate (DEA) was polymerized using an $N$-morpholine-functionalized trithiocarbonate-based RAFT chain transfer agent and subsequently chain-extended using NAEP to form a novel $\mathrm{pH}$-responsive diblock copolymer. Above the $\mathrm{p} K_{\mathrm{a}}$ of PDEA $(\sim 7.3)$, DLS and ${ }^{1} \mathrm{H}$ NMR studies indicated the formation of well-defined PDEA-core spherical micelles.
\end{abstract}

\section{INTRODUCTION}

Poly(N-vinylpyrrolidone) (PNVP) is a commercially important nonionic water-soluble polymer with a wide range of commercial applications. ${ }^{1,2}$ Its high dipole moment $(4.06 \mathrm{D})^{3}$ enables the efficient sequestration of many fugitive dyes and hence its widespread use as an anti-dye transfer agent in laundry formulations. ${ }^{4,5}$ PNVP can also be utilized as a filmforming agent in hair sprays ${ }^{6}$ and various cosmetics, and its excellent biocompatibility and relatively low cost account for its use as an excipient in drug formulations. ${ }^{6,7}$ Bulk copolymerization with other vinyl monomers enables the production of soft contact lenses ${ }^{8}$ while so-called "popcorn" polymerization of $\mathrm{N}$-vinylpyrrolidone (NVP) produces crosslinked particles that can be used to clarify alcoholic beverages such as beer and wine. ${ }^{9}$ PNVP can also be used as an emulsifier, ${ }^{10}$ a dispersant for $\beta$-carotene, ${ }^{11}$ or a steric stabilizer for the preparation of conducting polymer nanoparticles. ${ }^{12}$
NVP is an example of a less activated monomer (LAM). As such, it can be readily statistically copolymerized with comonomers such as vinyl acetate or acrylics. However, its copolymerization with methacrylics or styrene is more problematic, with strongly non-ideal behavior typically being observed. ${ }^{13-15}$ There are a number of literature reports of the reversible addition-fragmentation chain transfer (RAFT) polymerization of NVP using xanthates or dithiocarbamates. ${ }^{16-18}$ However, control is usually inferior to that achieved for (meth)acrylic monomers under optimized conditions, particularly for polymerizations performed in aqueous solution. ${ }^{19-25}$ For example, Guinaudeau et al. reported the successful RAFT/MADIX aqueous polymer-

Received: July 30, 2018

Revised: September 7, 2018

Published: September 25, 2018 
Scheme 1. Synthesis of PNAEP Homopolymers by RAFT Aqueous Solution Polymerization of 2- $(\mathrm{N}$ -

Acryloyloxy)ethylpyrrolidone (NAEP) Utilizing a Trithiocarbonate-Based RAFT Agent (DDMAT) and Either $\alpha, \alpha^{\prime}$ Azoisobutyronitrile (AIBN) or a Low-Temperature Redox Initiator System Based on a 1:1 Molar Ratio of Potassium Persulfate (KPS) and Ascorbic Acid (AsAc)

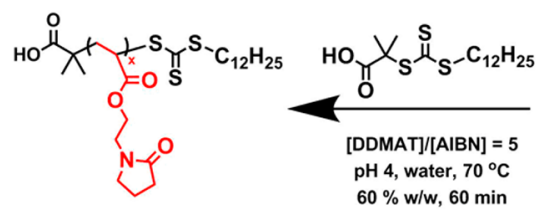

ization of PNVP-based double-hydrophilic diblock copolymers by employing redox initiation at ambient temperature. ${ }^{26,27}$ Using ascorbic acid led to the formation of $N-(\alpha-$ hydroxyethyl)pyrrolidone in acidic solution, but switching to sodium sulfite under mildly alkaline conditions $(\mathrm{pH} 9)$ prevented generation of this unwanted side product. Under the latter optimized conditions, relatively good control was achieved for the RAFT homopolymerization of NVP $\left(M_{\mathrm{w}} / M_{\mathrm{n}}\right.$ $<1.20$ ). However, a self-blocking chain extension experiment led to a final $M_{\mathrm{w}} / M_{\mathrm{n}}$ of 1.72 , which suggests imperfect control. Nevertheless, the synthesis of PNVP-based double-hydrophilic diblock copolymers was achieved by preparing the other hydrophilic block first, followed by NVP polymerization.

Notwithstanding these advances in the controlled polymerization of NVP, a methacrylic analogue (2-( $N$-methacryloyloxy)ethylpyrrolidone, NMEP) has been recently examined to address the copolymerizability problem. The latter monomer has been polymerized with good control using RAFT polymerization by Cunningham and co-workers. ${ }^{28-30}$ Poly(2( $N$-methacryloyloxy)ethylpyrrolidone (PNMEP) was subsequently used as a steric stabilizer block for the synthesis of diblock copolymer nano-objects via RAFT dispersion polymerization of benzyl methacrylate in ethano ${ }^{28}$ and also employed as a core-forming block for RAFT dispersion polymerization formulations conducted in $n$-dodecane. ${ }^{30}$ However, PNMEP is significantly less hydrophilic than PNVP, exhibiting inverse temperature solubility in aqueous solution at around $55^{\circ} \mathrm{C}$ in the high molecular weight limit. ${ }^{31,32}$ Indeed, this property was exploited by Cunningham and co-workers to devise a RAFT aqueous dispersion polymerization formulation in which the growing PNMEP chains formed the hydrated cores of sterically stabilized nanoparticles at $70{ }^{\circ} \mathrm{C}^{29}$ In view of such observations, PNMEP was considered to be unsuitable for use as a stabilizer block for either RAFT aqueous emulsion polymerization or RAFT aqueous dispersion polymerization because it did not confer sufficient steric stabilization. Given this restriction, a more hydrophilic analogue of NVP was sought, with one obvious candidate being 2-( $N$-acryloyloxy)ethylpyrrolidone (NAEP).

As far as we are aware, there has only been one report of the controlled polymerization of NAEP. ${ }^{33}$ In 2009 , Shi et al. reported the RAFT aqueous solution homopolymerization of NAEP using visible light irradiation at $25{ }^{\circ} \mathrm{C}$. Good control over the molecular weight distribution was demonstrated $\left(M_{\mathrm{w}} /\right.$ $\left.M_{\mathrm{n}}<1.10\right)$, but apparently NAEP conversions did not exceed $77 \%$. Herein we report the efficient synthesis of a series of near-monodisperse homopolymers via RAFT aqueous solution polymerization of NAEP using either a persulfate initiator at 30 ${ }^{\circ} \mathrm{C}$ or an azo initiator at $70^{\circ} \mathrm{C}$ (see Scheme 1). Optimized reaction conditions were then employed to prepare a series of new low-dispersity PNAEP-based diblock copolymers in excellent yield and with high blocking efficiencies. The

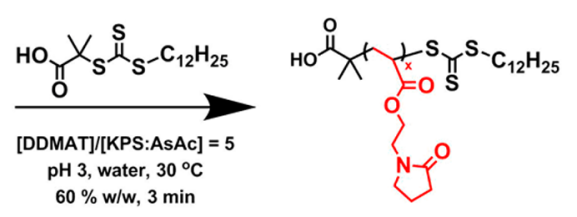

aqueous solution properties of some of these copolymers have been briefly explored.

\section{EXPERIMENTAL SECTION}

Materials. 2-(N-Acryloyloxy)ethylpyrrolidone (NAEP; 95\% purity) was kindly provided by Ashland Specialty Ingredients (Cherry Hill, NJ, USA) and was further purified through dilution with chloroform followed by sequential washes with $5 \% \mathrm{Na}_{2} \mathrm{CO}_{3}$ solution, saturated $\mathrm{NaCl}$ solution, and finally deionized water. Repeated washes with water were performed until the NAEP solution was neutralized. This solution was then dried over anhydrous $\mathrm{MgSO}_{4}$. All chemicals used for NAEP purification were purchased from Sigma-Aldrich (Dorset, UK) and were used as received. 2-Hydroxyethyl acrylate (HEA) was purchased from Sigma-Aldrich (Dorset, UK) and purified via 20 washes with $n$-hexane. Oligo(ethylene glycol) methyl ether acrylate (OEGA, $M_{\mathrm{n}} \approx 454 \mathrm{~g} \mathrm{~mol}^{-1}$ ), 2-(diethylamino)ethyl methacrylate (DEA), ascorbic acid (AsAc), potassium persulfate (KPS), $\alpha, \alpha^{\prime}$-azoisobutyronitrile (AIBN), 4,4'-azobis(4-cyanopentanoic acid) (ACVA; 99\%), and 2-(dodecylthiocarbonothioylthio)-2methylpropionic acid (DDMAT; 98\%) were purchased from SigmaAldrich (Dorset, UK) and used as received. N-Isopropylacrylamide (NIPAM; 97\%) was purchased from Sigma-Aldrich (Dorset, UK) and recrystallized from $n$-hexane twice before use. 4-Cyano-4-(2phenylethanesulfanylthiocarbonyl)sulfanylpentanoic acid (PETTC) was prepared and purified as reported elsewhere. ${ }^{34}$ MPETTC was then prepared from PETTC using a literature protocol. ${ }^{35} d_{4}$-Methanol and $\mathrm{D}_{2} \mathrm{O}$ were purchased from Goss Scientific Instruments Ltd. (Cheshire, UK). All other solvents were purchased from Fisher Scientific (Loughborough, UK) and used as received. Deionized water was used for all experiments.

RAFT Solution Homopolymerization of NAEP in Water at $70{ }^{\circ} \mathrm{C}$. A typical protocol for the synthesis of a PNAEP $_{80}$ homopolymer was as follows: NAEP (1.00 g, $5.46 \mathrm{mmol})$, DDMAT RAFT agent (24.9 $\mathrm{mg}$, $68.2 \mu \mathrm{mol}$; target $\mathrm{DP}=80)$, deionized water $(0.6847 \mathrm{~g}$, corresponding to a $60 \% \mathrm{w} / \mathrm{w}$ solution), and AIBN (2.2 mg, 13.6 $\mu$ mol; DDMAT/AIBN molar ratio $=5.0$ ) were weighed into a $14 \mathrm{~mL}$ vial charged with a magnetic flea. This reaction vial was then placed in an ice bath and degassed with nitrogen for $30 \mathrm{~min}$. Following this, the vial was then immersed in an oil bath set at $70{ }^{\circ} \mathrm{C}$, and the reaction solution was stirred for $50 \mathrm{~min}$, resulting in a final monomer conversion of $99 \%$ as judged by ${ }^{1} \mathrm{H}$ NMR spectroscopy. DMF GPC analysis indicated an $M_{\mathrm{n}}$ of $13300 \mathrm{~g} \mathrm{~mol}^{-1}$ and an $M_{\mathrm{w}} / M_{\mathrm{n}}$ of 1.14 .

RAFT Solution Homopolymerization of NAEP in Water at $30^{\circ} \mathrm{C}$. A typical protocol for the synthesis of a PNAEP $_{80}$ homopolymer was as follows: NAEP $(1.00 \mathrm{~g}, 5.46 \mathrm{mmol})$, DDMAT RAFT agent (24.9 $\mathrm{mg}$, $68.2 \mu \mathrm{mol}$; target DP $=80)$, and AsAc $(2.4 \mathrm{mg}, 13.6 \mu \mathrm{mol})$ were weighed into a $14 \mathrm{~mL}$ vial charged with a magnetic flea and degassed with nitrogen in an ice bath for $30 \mathrm{~min}$ (reaction solution 1). Deionized water $(0.6873 \mathrm{~g}$, corresponding to a $60 \% \mathrm{w} / \mathrm{w}$ solution) and KPS $(3.7 \mathrm{mg}, 13.6 \mu \mathrm{mol}$; DDMAT/KPS molar ratio $=5.0)$ were weighed into a separate $14 \mathrm{~mL}$ vial (reaction solution 2), sealed using a rubber septum and degassed with nitrogen in an ice bath for $30 \mathrm{~min}$. After $30 \mathrm{~min}$, the vial containing reaction solution 1 was immersed in an oil bath set at $30^{\circ} \mathrm{C}$. Following this, reaction solution 2 was added to this vial via a degassed syringe and needle to reaction solution 1 under nitrogen. The polymerization was monitored for $5 \mathrm{~min}$, resulting in a final monomer conversion of $99 \%$ as judged by ${ }^{1} \mathrm{H}$ NMR 
spectroscopy. DMF GPC analysis indicated an $M_{\mathrm{n}}$ of $12300 \mathrm{~g} \mathrm{~mol}^{-1}$ and an $M_{\mathrm{w}} / M_{\mathrm{n}}$ of 1.15. Targeting mean DPs above 150 required reaction times of up to $60 \mathrm{~min}$ for high conversion.

Preparation of PNAEP $P_{x}$ Macro-CTA. The typical protocol for the synthesis of a PNAEP $_{62}$ macro-CTA by RAFT aqueous solution polymerization was as follows: NAEP $(10.00 \mathrm{~g}, 54.6 \mathrm{mmol})$, DDMAT RAFT agent $(199.0 \mathrm{mg}, 0.5458 \mathrm{mmol}$; target DP $=100)$, and AsAc $(1.0 \mathrm{mg}, 5.5 \mu \mathrm{mmol})$ were weighed into a $14 \mathrm{~mL}$ vial charged with a magnetic flea (reaction solution 1). This reaction solution was then placed in an ice bath and degassed with nitrogen for $30 \mathrm{~min}$. Deionized water $(6.8010 \mathrm{~g}, 60 \% \mathrm{w} / \mathrm{w})$ and KPS (1.5 mg, $5.5 \mu \mathrm{mol}$; DDMAT/KPS molar ratio $=100)$ were weighed into a second $14 \mathrm{~mL}$ vial (reaction solution 2) and degassed with nitrogen in an ice bath for $30 \mathrm{~min}$. After $30 \mathrm{~min}$, the vial containing reaction solution 1 was immersed in an oil bath set at $30^{\circ} \mathrm{C}$. Reaction solution 2 was then added via a degassed syringe and needle to reaction solution 1 under nitrogen. The polymerization was allowed to proceed for $8 \mathrm{~min}$ before being quenched via exposure to air and immersed in an ice bath. ${ }^{1} \mathrm{H}$ NMR analysis of the disappearance of vinyl signals at 5.9 and $6.4 \mathrm{ppm}$ relative to the integrated four ethyl protons at $3.4-3.8 \mathrm{ppm}$ assigned to PNAEP indicated a monomer conversion of $60 \%$. The crude homopolymer was purified by precipitating into a 10 -fold excess of diethyl ether. This purification protocol was repeated twice to give a PNAEP macro-CTA containing $<1 \%$ residual monomer. Its mean degree of polymerization was calculated to be 62 as judged by ${ }^{1} \mathrm{H}$ NMR spectroscopy (comparison of the integral at 3.4-3.8 ppm (m, 4H) with that assigned to the methyl RAFT chain end at $0.86-0.96$ ppm $(\mathrm{t}, 3 \mathrm{H}))$. DMF GPC analysis indicated an $M_{\mathrm{n}}$ of $9800 \mathrm{~g} \mathrm{~mol}^{-1}$ and an $M_{\mathrm{w}} / M_{\mathrm{n}}$ of 1.25. Other PNAEP ${ }_{x}$ homopolymers were obtained by adjusting the NAEP/DDMAT molar ratio.

Synthesis of PNAEP ${ }_{62}-$ PHEA $_{x}$ Diblock Copolymers via RAFT Aqueous Solution Polymerization of HEA at $30^{\circ} \mathrm{C}$. A typical protocol used for the synthesis of the PNAEP $_{62}-$ PHEA $_{100}$ diblock copolymer was as follows: PNAEP $_{62}$ macro-CTA (0.250 g, 21.3 $\mu \mathrm{mol})$, HEA (0.2476 g, $2.1324 \mathrm{mmol}$; target DP $=100)$, and AsAc $(0.8 \mathrm{mg}, 4.3 \mu \mathrm{mol})$ were weighed into a $14 \mathrm{~mL}$ vial charged with a magnetic flea (reaction solution 1). This vial was immersed in an ice bath, and the solution was degassed with nitrogen for $30 \mathrm{~min}$. Deionized water $(2.2306 \mathrm{~g}$, corresponding to a $15 \% \mathrm{w} / \mathrm{w}$ solution) and $\mathrm{KPS}\left(1.2 \mathrm{mg}, 4.3 \mu \mathrm{mol}\right.$; $\mathrm{PNAEP}_{62}$ macro-CTA $/ \mathrm{KPS}$ molar ratio $=$ 5.0) were weighed into a separate $14 \mathrm{~mL}$ vial (reaction solution 2) and degassed with nitrogen in an ice bath for $30 \mathrm{~min}$. Reaction solution 1 was then immersed in an oil bath set at $30{ }^{\circ} \mathrm{C}$. Reaction solution 2 was added to this vial via a degassed syringe and needle under nitrogen. The polymerization was allowed to proceed for $18 \mathrm{~h}$ before being quenched by exposing the reaction solution to air and immersing the reaction vial in an ice bath. ${ }^{1} \mathrm{H}$ NMR studies indicated more than $99 \%$ conversion while DMF GPC analysis indicated a $M_{\mathrm{n}}$ of $29400 \mathrm{~g} \mathrm{~mol}^{-1}$ and an $M_{\mathrm{w}} / M_{\mathrm{n}}$ of 1.22 . Other diblock copolymer compositions were obtained by adjusting the HEA/PNAEP 62 molar ratio to target PHEA DPs of 50 to 400 .

Synthesis of PNAEP $71-P O E G A_{x}$ Diblock Copolymers via RAFT Aqueous Solution Polymerization of OEGA at $30^{\circ} \mathrm{C}$. A typical protocol used for the synthesis of the $\mathrm{PNAEP}_{71}-\mathrm{POEGA}_{40}$ diblock copolymer was as follows: PNAEP $_{71}$ macro-CTA $(0.250 \mathrm{~g}, 21.3$ $\mu \mathrm{mol})$, OEGA $(0.3872 \mathrm{~g}, 853 \mu \mathrm{mol}$; target DP $=40)$, and AsAc $(0.8$ $\mathrm{mg}, 4.3 \mu \mathrm{mol}$ ) were weighed into a $14 \mathrm{~mL}$ vial charged with a magnetic flea (reaction solution 1). This vial was placed in an ice bath, and the solution was degassed with nitrogen for $30 \mathrm{~min}$. Deionized water (2.3066 g, corresponding to a $20 \% \mathrm{w} / \mathrm{w}$ solution) and KPS (1.2 $\mathrm{mg}, 4.3 \mu \mathrm{mol}$; PNAEP $_{71}$ macro-CTA/KPS molar ratio $\left.=5.0\right)$ were weighed into a separate $14 \mathrm{~mL}$ vial (reaction solution 2) and degassed with nitrogen using an ice bath for $30 \mathrm{~min}$. Reaction solution 1 was immersed in an oil bath set at $30^{\circ} \mathrm{C}$. Reaction solution 2 was then added to this vial via a degassed syringe and needle under nitrogen. ${ }^{1} \mathrm{H}$ NMR studies indicated more than $99 \%$ conversion while DMF GPC analysis indicated an $M_{\mathrm{n}}$ of $20400 \mathrm{~g} \mathrm{~mol}^{-1}$ and an $M_{\mathrm{w}} / M_{\mathrm{n}}$ of 1.27. Other diblock copolymer compositions were obtained by adjusting the $\mathrm{OEGA} / \mathrm{PNAEP}_{71}$ macro-CTA molar ratio to give target POEGA DPs ranging from 50 to 400 .
Synthesis of PNAEP $_{95}-$ PNIPAM $_{x}$ Diblock Copolymers via RAFT Aqueous Solution Polymerization of NIPAM at $22{ }^{\circ} \mathrm{C}$ Using a PNEAP ${ }_{95}$ Macro-CTA. A typical protocol used for the synthesis of the PNAEP $_{95}-$ PNIPAM $_{100}$ diblock copolymer was as follows: PNAEP $_{95}$ macro-CTA $(0.250 \mathrm{~g}, 14.1 \mu \mathrm{mol})$, NIPAM $(0.159 \mathrm{~g}, 141 \mu \mathrm{mol}$; target $\mathrm{DP}=100)$, and AsAc $(0.50 \mathrm{mg}, 2.8 \mu \mathrm{mol})$ were weighed into a $14 \mathrm{~mL}$ vial charged with a magnetic flea (reaction solution 1 ). This vial was placed in an ice bath, and the solution was degassed with nitrogen for $30 \mathrm{~min}$. Deionized water (1.6393 g, corresponding to a $20 \% \mathrm{w} / \mathrm{w}$ solution) and KPS $(0.76 \mathrm{mg}, 2.8 \mu \mathrm{mol}$; PNAEP 95 macro-CTA/KPS molar ratio $=5.0)$ were weighed into a separate $14 \mathrm{~mL}$ vial (reaction solution 2) and degassed with nitrogen using an ice bath for $30 \mathrm{~min}$. Reaction solution 1 was immersed in an oil bath set at $22{ }^{\circ} \mathrm{C}$. Reaction solution 2 was then added to this vial via a degassed syringe and needle under nitrogen. ${ }^{1} \mathrm{H}$ NMR studies indicated more than $99 \%$ conversion while DMF GPC analysis yielded an $M_{\mathrm{n}}$ of $20400 \mathrm{~g} \mathrm{~mol}^{-1}$ and an $M_{\mathrm{w}} / M_{\mathrm{n}}$ of 1.21. Other diblock copolymer compositions were obtained by adjusting the NIPAM/PNAEP ${ }_{95}$ macro-CTA molar ratio to give target PNIPAM DPs ranging from 100 to 300 .

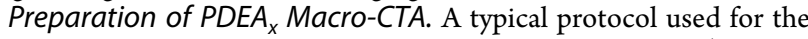
synthesis of the PDEA ${ }_{x}$ homopolymer was as follows: DEA (10.00 g, $54.0 \mathrm{mmol})$, MPETTC RAFT agent $(244.1 \mathrm{mg}, 0.540 \mathrm{mmol}$; target $\mathrm{DP}=100)$, ACVA $(50.4 \mathrm{mg}, 180 \mu \mathrm{mol}$; MPETTC/ACVA molar ratio $=3.0)$, and THF $(6.86 \mathrm{~g}$, corresponding to a $60 \% \mathrm{w} / \mathrm{w}$ solution $)$ were weighed into a $50 \mathrm{~mL}$ round-bottom flask charged with a magnetic flea. This flask was placed in an ice bath and degassed with nitrogen for $30 \mathrm{~min}$ before being immersed in an oil bath set at $70^{\circ} \mathrm{C}$. The polymerization was allowed to proceed for $190 \mathrm{~min}$, affording a monomer conversion of $95 \%$ as judged by ${ }^{1} \mathrm{H}$ NMR. The crude homopolymer was purified by precipitation into a 10 -fold excess of mildly alkaline water ( $\mathrm{pH} \mathrm{10)}$. This neutral PDEA homopolymer was then dried under vacuum before being protonated using an aqueous solution of $1.0 \mathrm{M} \mathrm{HCl}$. The fully protonated PDEA homopolymer was isolated in its $\mathrm{HCl}$ salt via precipitation into a 10 -fold excess of acetone. This homopolymer was then dried in a vacuum oven to afford a PDEA macro-CTA containing $<1 \%$ residual monomer. Its mean degree of polymerization was determined to be 99 by ${ }^{1} \mathrm{H}$ NMR spectroscopy (integral at 3.90-4.14 ppm (t, $2 \mathrm{H}, \mathrm{O}-\mathrm{CH}_{2}-\mathrm{CH}_{2} \mathrm{~N}$ ) was compared to that assigned to the aromatic RAFT chain-end protons at 7.2-7.3 ppm $(\mathrm{m}, 5 \mathrm{H}))$. Chloroform GPC analysis indicated an $M_{\mathrm{n}}$ of $10800 \mathrm{~g} \mathrm{~mol}^{-1}$ and an $M_{\mathrm{w}} / M_{\mathrm{n}}$ of 1.24 .

Synthesis of PDEA $100-P N A E P_{y}$ Diblock Copolymers via RAFT Aqueous Solution Polymerization of NAEP at $30 \% \mathrm{w} / \mathrm{w}$ Solids Using a PDEA 100 Macro-CTA at $p H$ 2. A typical protocol used for the synthesis of the $\mathrm{PDEA}_{100}-\mathrm{PNAEP}_{100}$ diblock copolymer via RAFT aqueous solution polymerization of NAEP was as follows: PDEA $_{100}$ macro-CTA $(200 \mathrm{mg}, 10.5 \mu \mathrm{mol})$, NAEP $(190 \mathrm{mg}, 1.054 \mathrm{mmol}$; target DP $=100)$, and AsAc $(0.37 \mathrm{mg}, 2.1 \mu \mathrm{mol})$ were weighed into a $14 \mathrm{~mL}$ vial charged with a magnetic flea (reaction solution 1). This vial was immersed in an ice bath and degassed with nitrogen for 30 min. Dilute aqueous $\mathrm{HCl}(0.001 \mathrm{M}, 1.12 \mathrm{~g})$ and $\mathrm{KPS}(57 \mathrm{mg}, 2.1$ $\mu \mathrm{mol} ; \mathrm{PDEA}_{100}$ macro-CTA/KPS molar ratio $\left.=5.0\right)$ were weighed into a separate $14 \mathrm{~mL}$ vial (reaction solution 2; final $\mathrm{pH} 2$ ), which was immersed in an ice bath and degassed with nitrogen for $30 \mathrm{~min}$. The vial containing reaction solution 1 was then immersed in an oil bath set at $30{ }^{\circ} \mathrm{C}$. Reaction solution 2 was added to this vial using a degassed syringe/needle under nitrogen to afford a final solution at $\mathrm{pH} 2$ targeting $30 \% \mathrm{w} / \mathrm{w}$ solids. ${ }^{1} \mathrm{H}$ NMR studies indicated that an NAEP conversion of $99 \%$ was achieved after $120 \mathrm{~min}$. DMF GPC analysis indicated an $M_{\mathrm{n}}$ of $39500 \mathrm{~g} \mathrm{~mol}^{-1}$ and an $M_{\mathrm{w}} / M_{\mathrm{n}}$ of 1.27 . Other diblock copolymer compositions were obtained by adjusting the NAEP/PDEA 100 macro-CTA molar ratio to give target PNAEP DPs ranging from 50 to 100 .

Copolymer Characterization. ${ }^{1} \mathrm{H}$ NMR Spectroscopy. ${ }^{1} \mathrm{H}$ NMR spectra were recorded at $25{ }^{\circ} \mathrm{C}$ in $d_{4}$-methanol and $\mathrm{D}_{2} \mathrm{O}$ using a 400 $\mathrm{MHz}$ Bruker Avance-400 spectrometer (64 scans averaged per spectrum).

Gel Permeation Chromatography (GPC). The molecular weights and dispersities of the homopolymers series and diblock copolymers were determined by using an Agilent 1260 Infinity setup comprising 
two Polymer Laboratories PL gel $5 \mu \mathrm{m}$ Mixed-C columns and a refractive index detector operating at $60^{\circ} \mathrm{C}$. The mobile phase was HPLC-grade DMF containing $10 \mathrm{mmol} \mathrm{LiBr}$ at a flow rate of $1.0 \mathrm{~mL}$ $\mathrm{min}^{-1}$. Ten near-monodisperse poly(methyl methacrylate) standards (PMMA; $M_{\mathrm{n}}=625$ to $618000 \mathrm{~g} \mathrm{~mol}^{-1}$ ) were used for calibration. The molecular weight and dispersity of the $\mathrm{PDEA}_{99}$ homopolymer was determined by using an Agilent 1260 Infinity setup comprising two Polymer Laboratories PL gel $5 \mu \mathrm{m}$ Mixed-C columns and a refractive index detector operating at $35{ }^{\circ} \mathrm{C}$. The mobile phase was HPLCgrade chloroform containing $0.25 \% \mathrm{v} / \mathrm{v}$ TEA at a flow rate of $1.0 \mathrm{~mL}$ $\min ^{-1}$. Ten near-monodisperse poly(methyl methacrylate) standards (PMMA; $M_{\mathrm{n}}=625$ to $618000 \mathrm{~g} \mathrm{~mol}^{-1}$ ) were used for calibration. The molecular weights and dispersities of the $\mathrm{PDEA}_{100}-\mathrm{PNAEP}_{y}$ diblock copolymers were determined by using an Agilent 1260 Infinity setup comprising two Polymer Laboratories PL gel $5 \mu \mathrm{m}$ Mixed-C columns and a refractive index detector operating at $60{ }^{\circ} \mathrm{C}$. The mobile phase was HPLC-grade DMF containing $0.25 \% \mathrm{v} / \mathrm{v}$ TEA and $10 \mathrm{mmol} \mathrm{LiBr}$ at a flow rate of $1.0 \mathrm{~mL} \mathrm{~min}{ }^{-1}$. Ten near-monodisperse poly(methyl methacrylate) standards (PMMA; $M_{\mathrm{n}}=625$ to $618000 \mathrm{~g} \mathrm{~mol}^{-1}$ ) were used for calibration.

Differential Scanning Calorimetry (DSC). Glass transition temperatures for four PNAEP homopolymers were determined using a Pyris 1 Perkin-Elmer differential scanning calorimeter operating over a temperature range from -30 to $70{ }^{\circ} \mathrm{C}$ at a rate of $10^{\circ} \mathrm{C} \mathrm{min}{ }^{-1}$. Each $10 \mathrm{mg}$ sample was freeze-dried and subsequently dried for $24 \mathrm{~h}$ in a vacuum oven prior to analysis. Dried samples were hermetically sealed in a vented aluminum pan, and the instrument was calibrated for heat flow and temperature using both indium and zinc standards. Two heating-cooling cycles were performed: the first cycle ensured removal of residual water, and the glass transition temperature was determined during the second cycle.

Visible Absorption Spectroscopy. Spectra were recorded from 400 to $800 \mathrm{~nm}$ for $1.0 \% \mathrm{w} / \mathrm{w}$ aqueous solutions of various PNAEP and PNMEP homopolymers between 20 and $80{ }^{\circ} \mathrm{C}$ at $5{ }^{\circ} \mathrm{C}$ increments using a Shimadzu UV-1800 spectrometer. An increase in turbidity at $600 \mathrm{~nm}$ indicated the lower critical solution temperature (LCST) of the polymer, if applicable.

Dynamic Light Scattering (DLS). DLS studies were conducted using a Malvern Instruments Zetasizer Nano series instrument equipped with a $4 \mathrm{~mW} \mathrm{He}-\mathrm{Ne}$ laser $(\lambda=633 \mathrm{~nm})$ and an avalanche photodiode detector. Scattered light was detected at $173^{\circ}$. Intensityaverage hydrodynamic diameters were calculated via the StokesEinstein equation.

\section{RESULTS AND DISCUSSION}

RAFT polymerizations of methacrylic monomers are often more well-controlled compared to their acrylic counterparts, since the latter tend to undergo chain transfer to polymer. ${ }^{36,37}$ In an attempt to optimize the RAFT homopolymerization of NAEP in water, kinetic studies were conducted using a lowtemperature redox initiator at $30{ }^{\circ} \mathrm{C}$ or AIBN initiator at $70{ }^{\circ} \mathrm{C}$ (see Scheme 1 and Figure 1). In both cases, DDMAT was chosen as the trithiocarbonate-based chain transfer agent (CTA), and a degree of polymerization (DP) of 200 was targeted. Furthermore, a relatively high NAEP concentration of $60 \% \mathrm{w} / \mathrm{w}$ was selected to solubilize the hydrophobic DDMAT. It was envisaged that the low-temperature redox initiator system would confer various benefits, including fewer side reactions, minimal induction periods, and greater RAFT control. $^{38}$

Aliquots of each reaction mixture were taken at regular intervals, and monomer conversions were determined by ${ }^{1} \mathrm{H}$ NMR analysis. When using AIBN at $70{ }^{\circ} \mathrm{C}$, more than $95 \%$ NAEP conversion was achieved within $60 \mathrm{~min}$, despite a brief induction period. Remarkably, NAEP polymerizations conducted using the redox initiator at $30{ }^{\circ} \mathrm{C}$ proceeded to more than $90 \%$ conversion within just $5 \mathrm{~min}$ with no discernible

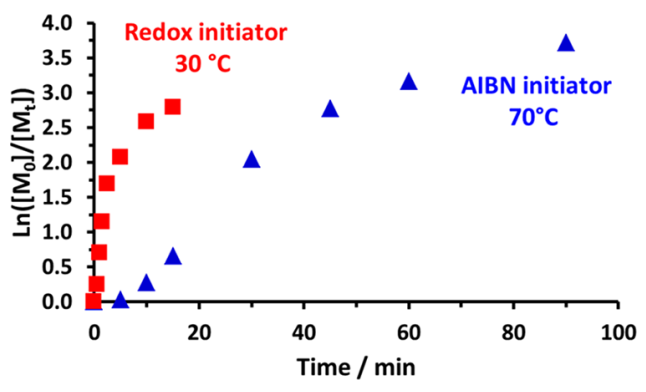

Figure 1. Semilogarithmic plots obtained for the RAFT aqueous solution polymerization of NAEP using a DDMAT/initiator molar ratio of 5.0 where the initiator is either AIBN (triangles) at $70{ }^{\circ} \mathrm{C}$ or $\mathrm{KPS} / \mathrm{AsAc}$ (squares) at $30^{\circ} \mathrm{C}$. Target degree of polymerization $=200$ at $60 \% \mathrm{w} / \mathrm{w}$ solids.

induction period. Moreover, comparing the initial gradients of the linear regions of the respective semilogarithmic plots (Figure 1) indicated that the rate of polymerization at $30^{\circ} \mathrm{C}$ was an order of magnitude faster than that at $70{ }^{\circ} \mathrm{C}$ (see Figure S1).

DMF GPC was used to monitor the evolution of molecular weight during the RAFT aqueous solution polymerization of NAEP at 30 or $70{ }^{\circ} \mathrm{C}$ (Figure 2). In both cases, relatively high

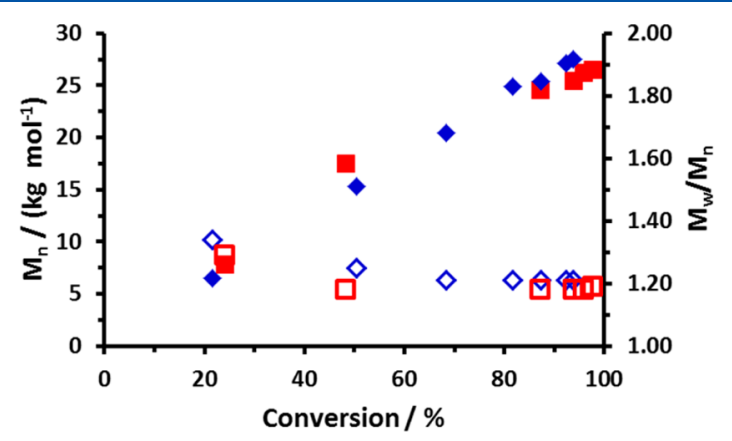

Figure 2. Evolution of $M_{\mathrm{n}}$ (filled symbols) and $M_{\mathrm{w}} / M_{\mathrm{n}}$ (open symbols) vs conversion for the RAFT aqueous solution polymerization of PNAEP ${ }_{200}$ homopolymer at either $30{ }^{\circ} \mathrm{C}$ (diamonds) or 70 ${ }^{\circ} \mathrm{C}$ (squares). In both cases, the DDMAT/initiator molar ratio was 5.0 (GPC protocol: DMF eluent; refractive index detector; calibration against a series of near-monodisperse PMMA standards).

dispersities $\left(M_{\mathrm{w}} / M_{\mathrm{n}}>1.30\right)$ were observed during the initial stages (below $40 \%$ conversion). Exotherms of up to $25{ }^{\circ} \mathrm{C}$ were observed during RAFT syntheses conducted at $30{ }^{\circ} \mathrm{C}$ (see Figure S2), and the polymerizing solutions became highly viscous, with transparent yellow gels being obtained at high conversions when performing such syntheses at $60 \% \mathrm{w} / \mathrm{w}$. Perhaps surprisingly, relatively low final dispersities $\left(M_{\mathrm{w}} / M_{\mathrm{n}}<\right.$ 1.20) were observed for both PNAEP $_{200}$ homopolymers, despite the much faster rate of polymerization achieved at 30 ${ }^{\circ} \mathrm{C}$. To examine whether the RAFT polymerization of NAEP was well-controlled, a series of PNAEP homopolymers were prepared targeting a range of DPs using either AIBN or the low-temperature redox initiator (see Table 1). A DDMAT/ initiator molar ratio of 5.0 was used for all these homopolymerizations. DMF GPC analysis was used to determine the $M_{\mathrm{n}}$ and $M_{\mathrm{w}} / M_{\mathrm{n}}$ values in each case.

${ }^{1} \mathrm{H}$ NMR analysis indicated that high NAEP conversions $(\geq 98 \%)$ were achieved using either AIBN at $70{ }^{\circ} \mathrm{C}$ or the redox initiator at $30{ }^{\circ} \mathrm{C}$ when targeting PNAEP DPs of up to 120 or 400 , respectively. These results represent a substantial 
Table 1. Summary of Target PNAEP DP, Conversions, Molecular Weights $\left(M_{n}\right)$, and Dispersities $\left(M_{w} / M_{n}\right)$ Obtained for PNAEP Homopolymers Prepared by RAFT Aqueous Solution Polymerization of NAEP at Either $30^{\circ} \mathrm{C}$ (Low-Temperature Redox Initiator) or $70{ }^{\circ} \mathrm{C}(\mathrm{AIBN})$ at $60 \% \mathrm{w} / \mathrm{w}$ Solids

\begin{tabular}{ccccc} 
target PNAEP DP & conv $(\%)$ & temp $\left({ }^{\circ} \mathrm{C}\right)$ & $M_{\mathrm{n}}\left(\mathrm{g} \mathrm{mol}^{-1}\right)$ & $M_{\mathrm{w}} / M_{\mathrm{n}}$ \\
PNAEP $_{40}$ & 99 & 70 & 7600 & 1.13 \\
PNAEP $_{60}$ & 99 & 70 & 11200 & 1.13 \\
PNAEP $_{80}$ & 99 & 70 & 13300 & 1.14 \\
PNAEP $_{100}$ & 99 & 70 & 15700 & 1.19 \\
PNAEP $_{120}$ & 99 & 70 & 19300 & 1.15 \\
PNAEP $_{40}$ & 99 & 30 & 7400 & 1.19 \\
PNAEP $_{60}$ & 99 & 30 & 10000 & 1.15 \\
PNAEP $_{80}$ & 99 & 30 & 12300 & 1.15 \\
PNAEP $_{100}$ & 98 & 30 & 15200 & 1.15 \\
PNAEP $_{120}$ & 98 & 30 & 17100 & 1.16 \\
PNAEP $_{150}$ & 99 & 30 & 21500 & 1.15 \\
PNAEP $_{200}$ & 99 & 30 & 27600 & 1.16 \\
PNAEP $_{400}$ & 99 & 30 & 41400 & 1.18 \\
PNAEP $_{750}$ & 75 & 30 & 74600 & 1.26 \\
PNAEP $_{1000}$ & 70 & 30 & 115400 & 1.28 \\
\hline
\end{tabular}

improvement over the data previously reported by Shi et al., who reported $77 \%$ conversion within $35 \mathrm{~min}$ at $25^{\circ} \mathrm{C}$ for the visible light-mediated RAFT aqueous solution polymerization of NAEP at $50 \% \mathrm{w} / \mathrm{w}$ at $\mathrm{pH} 2.6 .^{33}$ DMF GPC analysis indicated that the $M_{\mathrm{n}}$ values for the final PNAEP $_{x}$ homopolymers increased linearly with target DP, as expected. Moreover, monomodal GPC traces and narrow molecular weight distributions $\left(M_{\mathrm{w}} / M_{\mathrm{n}}<1.20\right)$ were observed in all cases (see Figure 3). As discussed above for PNAEP syntheses

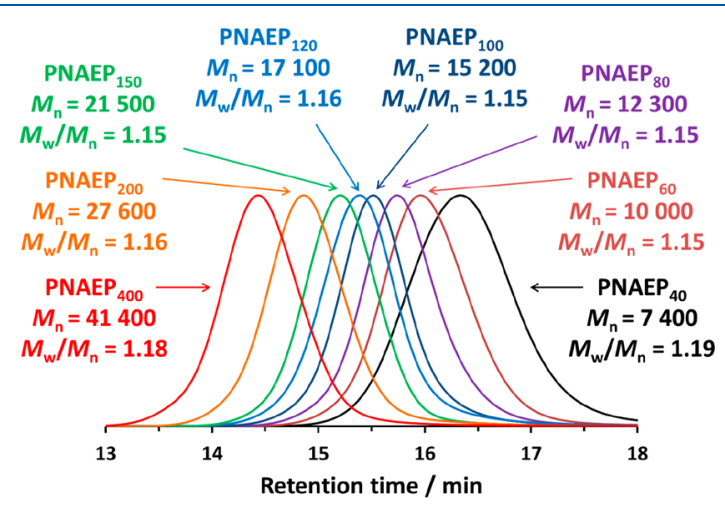

Figure 3. DMF GPC curves obtained for a series of $\operatorname{PNAEP}_{x}$ homopolymers prepared via RAFT solution polymerization of NAEP using KPS/AsAc redox initiator at $30{ }^{\circ} \mathrm{C}$ (calibrated against a series of near-monodisperse poly(methyl methacrylate) standards).

targeting a DP of 200, the faster rate of polymerization achieved at $30{ }^{\circ} \mathrm{C}$ did not adversely affect RAFT control over these polymerizations, with $M_{\mathrm{w}} / M_{\mathrm{n}}$ remaining less than 1.20 up to DP 400. Thus, the low-temperature redox initiator route was adopted for all subsequent RAFT syntheses. When targeting DPs above 400, reaction solutions became very viscous when using $60 \% \mathrm{w} / \mathrm{w}$ NAEP, which led to significantly lower conversions $(<80 \%$; see Table 1$)$.

Recently, Cunningham and co-workers reported that PNMEP homopolymers exhibited inverse temperature solubility behavior in aqueous solution. ${ }^{29}$ The lower critical solution temperature (LCST) or cloud point can be monitored by turbidimetry. For example, a $1.0 \% \mathrm{w} / \mathrm{w}$ aqueous solution of PNMEP $_{55}$ becomes turbid when heated to $62{ }^{\circ} \mathrm{C}$ (see Figure 4). ${ }^{39}$ In striking contrast, a $1.0 \% \mathrm{w} / \mathrm{w}$ aqueous solution of PNAEP $_{55}$ exhibits no LCST behavior and remains fully watersoluble up to at least $90{ }^{\circ} \mathrm{C}$ (see Figure 4). Clearly, the acrylic analogue is significantly more hydrophilic, which is not unexpected. This is important because such PNAEP $_{x}$ homopolymers should enable the convenient preparation of a range of new double-hydrophilic pyrrolidone-based diblock copolymers in aqueous solution. This possibility is explored below.

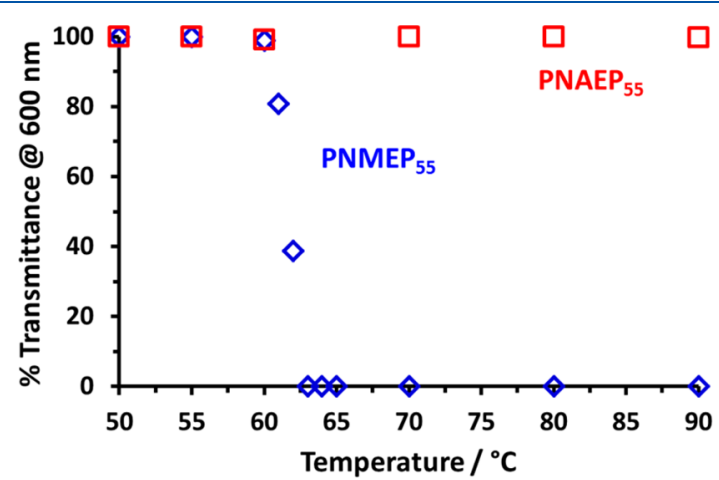

Figure 4. \% Transmittance (at $600 \mathrm{~nm}$ ) vs temperature plot recorded for a $1.0 \% \mathrm{w} / \mathrm{w}$ aqueous solution of a $\mathrm{PNMEP}_{55}$ homopolymer (blue diamonds) compared to that for a $1.0 \% \mathrm{w} / \mathrm{w}$ aqueous solution of a PNAEP $_{55}$ homopolymer (red squares). PNMEP $_{55}$ has an LCST at 62 ${ }^{\circ} \mathrm{C}$, whereas the more hydrophilic PNAEP $_{55}$ exhibits no discernible LCST behavior over this temperature range.

Glass transition temperatures $\left(T_{\mathrm{g}}\right)$ for four $\mathrm{PNAEP}_{x}$ homopolymers prepared via RAFT aqueous solution polymerization of NAEP utilizing the low-temperature redox initiator were determined using differential scanning calorimetry (DSC) for DPs ranging between 50 and 400. This technique indicated $T_{\mathrm{g}}$ values below room temperature for mean DPs of less than 400 (see Figure 5). A $T_{\mathrm{g}}$ of $\sim 19.6{ }^{\circ} \mathrm{C}$ was obtained for a

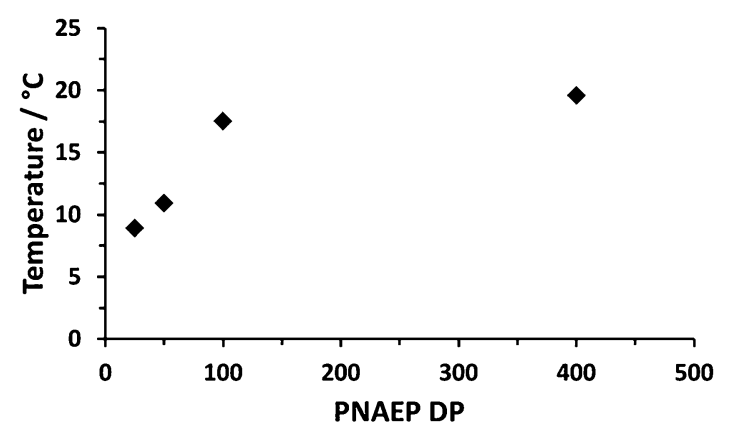

Figure 5. Variation of glass transition temperature with PNAEP DP

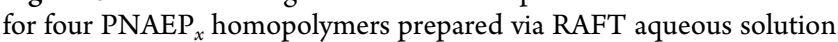
polymerization of NAEP at $30^{\circ} \mathrm{C}$.

PNAEP $_{400}$ homopolymer, which appears to lie close to the $T_{\mathrm{g}}$ for the high molecular weight limit. ${ }^{40}$ Such $T_{\mathrm{g}}$ values are significantly lower than those of PNMEP and suggest that the film-forming properties of PNAEP homopolymer at ambient temperature may be of potential commercial interest.

RAFT Aqueous Solution Polymerization of Either HEA or OEGA at $30{ }^{\circ} \mathrm{C}$ Using a PNAEP $_{x}$ Macro-CTA. A 
PNAEP $_{62}$ macro-CTA was prepared via RAFT aqueous solution polymerization of NAEP at $30{ }^{\circ} \mathrm{C}$ using a DDMAT/KPS molar ratio of 100 and targeting a DP of 100 . This much higher CTA/initiator molar ratio was selected in view of the relatively fast rate of polymerization observed for a CTA/initiator molar ratio of 5.0 and was designed to ensure maximum RAFT end-group fidelity. The resulting macro-CTA was purified via successive precipitation into excess diethyl ether. ${ }^{1} \mathrm{H}$ NMR end-group analysis of the methyl proton signals assigned to the RAFT chain-ends indicated a mean DP of 62 . Given the final NAEP conversion of $60 \%$, this indicates a RAFT agent efficiency of 97\%. DMF GPC analysis indicated an $M_{\mathrm{n}}$ of $9800 \mathrm{~g} \mathrm{~mol}^{-1}$ and a relatively narrow molecular weight distribution $\left(M_{\mathrm{w}} / M_{\mathrm{n}}<1.25\right)$. This PNAEP $_{62}$ macroCTA was subsequently used to prepare a series of PNAEP $_{62}-$ PHEA $_{x}$ diblock copolymers via RAFT aqueous solution polymerization of HEA (see Scheme 2a) targeting PHEA

Scheme 2. Synthesis of (a) PNAEP $_{62}-$ PHEA $_{x}$ Diblock Copolymers and (b) PNAEP $_{71}-$ POEGA $_{x}$ Diblock Copolymers by RAFT Aqueous Solution Polymerization of Either HEA or OEGA at $30^{\circ} \mathrm{C}$

(a)

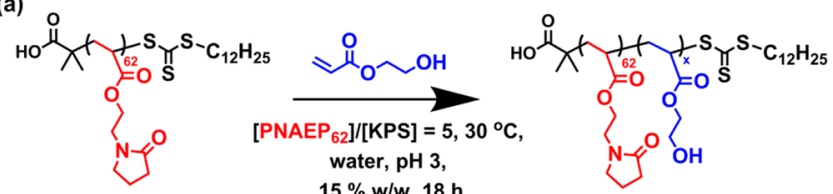

(b)

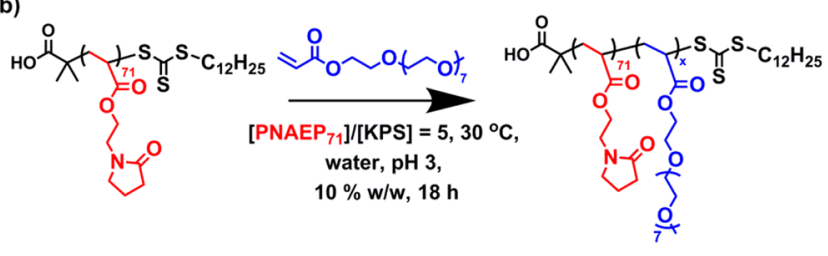

DPs of between 50 and 400. A DDMAT/KPS molar ratio of 5.0 was used in all cases. ${ }^{1} \mathrm{H}$ NMR studies indicated that high HEA conversions (>99\%) were achieved within $18 \mathrm{~h}$. Furthermore, DMF GPC analysis of the resulting PNAEP $_{62}-$ $\mathrm{PHEA}_{x}$ diblock copolymers indicated a linear increase in $M_{\mathrm{n}}$ with increasing PHEA DP (Figure 6a). Relatively low dispersities $\left(M_{\mathrm{w}} / M_{\mathrm{n}}<1.35\right)$ were obtained for all PNAEP $_{62}-$ PHEA $_{x}$ diblock copolymers. Moreover, comparison with the GPC trace recorded for the PNAEP $_{62}$ macro-CTA confirmed high blocking efficiencies in each case.

A second batch of PNAEP $_{71}$ macro-CTA was prepared via RAFT aqueous solution polymerization using a similar protocol to that described above. In this case, ${ }^{1} \mathrm{H}$ NMR endgroup analysis of the three methyl proton signals assigned to the RAFT chain end indicated a mean DP of $71(69 \%$ conversion, CTA efficiency $=97 \%)$. DMF GPC analysis indicated an $M_{\mathrm{n}}$ of $11200 \mathrm{~g} \mathrm{~mol}^{-1}$ and a $M_{\mathrm{w}} / M_{\mathrm{n}}$ of 1.17 . This PNAEP $_{71}$ macro-CTA was subsequently utilized for the RAFT aqueous solution polymerization of OEGA, targeting POEGA DPs between 50 and 400 and using a DDMAT/KPS molar ratio of 5.0 (see Scheme 2b). OEGA conversions of at least 99\% were achieved for all PNAEP $_{71}-$ POEGA $_{x}$ diblock copolymers within $18 \mathrm{~h}$ at $30{ }^{\circ} \mathrm{C}$, as judged by ${ }^{1} \mathrm{H} \mathrm{NMR}$. DMF GPC analyses of this series of PNAEP $_{71}-$ POEGA $_{x}$ diblock copolymers indicated a monotonic increase in $M_{n}$ with increasing POEGA DP, as expected. However, there is some discrepancy between the experimental and theoretical $M_{n}$
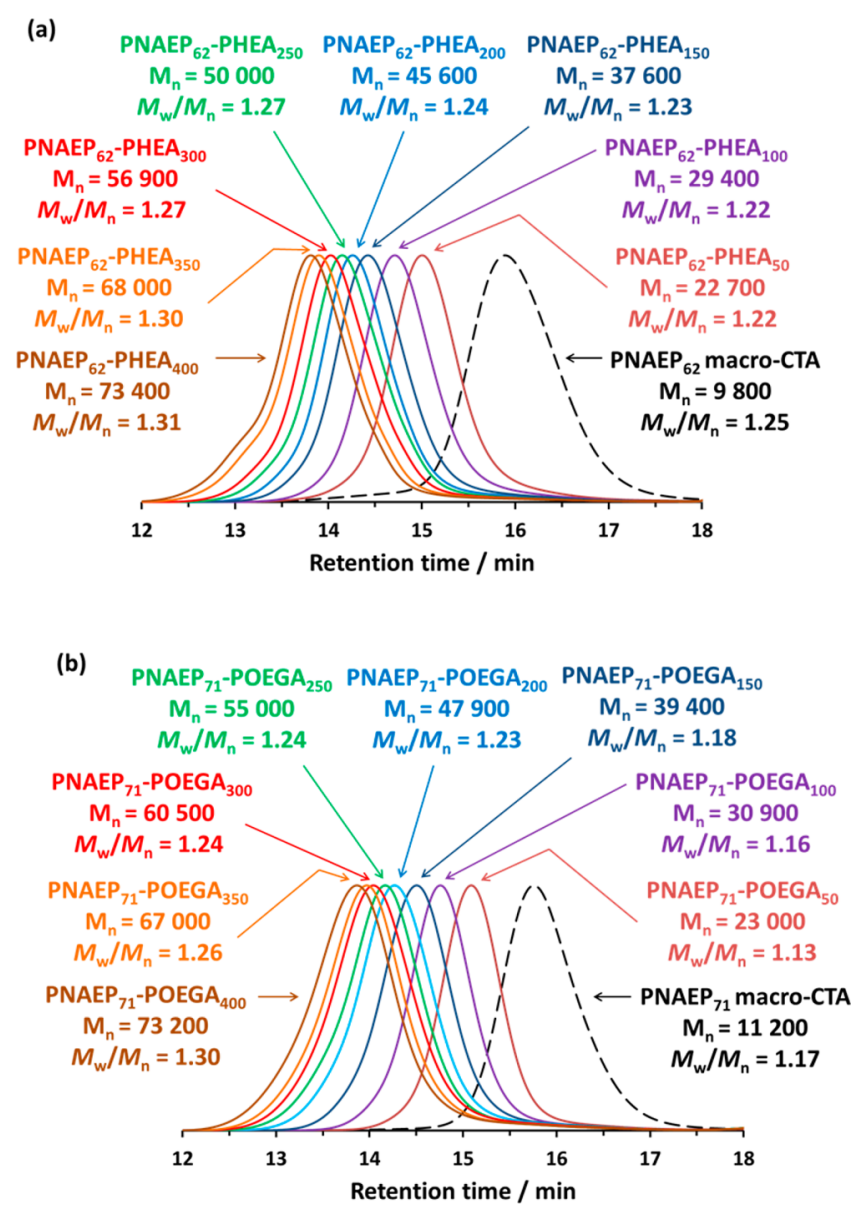

Figure 6. DMF GPC curves obtained for (a) a series of PNAEP $_{62}-$ PHEA $_{x}$ diblock copolymers and the corresponding PNAEP 62 macroCTA (dashed trace) and (b) a series of PNAEP $_{71}-$ POEGA $_{x}$ diblock copolymers and the corresponding PNAEP $_{71}$ macro-CTA (dashed trace).

values. Bearing in mind the brush-like nature of the POEGA block, this can be attributed to the poly(methyl methacrylate) standards used for GPC calibration. Nevertheless, relatively low dispersities $\left(M_{\mathrm{w}} / M_{\mathrm{n}}<1.30\right)$ were achieved for this PNAEP $_{71}-$ POEGA $_{x}$ diblock copolymer series, which suggests good RAFT control. Moreover, comparison of the GPC traces obtained for these PNAEP $_{71}-$ POEGA $_{x}$ diblock copolymers with that of the precursor PNAEP $_{71}$ macro-CTA indicated high blocking efficiencies (Figure 6b).

RAFT Aqueous Solution Polymerization of NIPAM at $22{ }^{\circ} \mathrm{C}$ Using a PNAEP $_{95}$ Macro-CTA. A third batch of PNAEP $_{95}$ macro-CTA was prepared via RAFT aqueous solution polymerization. In this case, ${ }^{1} \mathrm{H}$ NMR spectroscopy end-group analysis of the three methyl proton signals assigned to the RAFT chain-end indicated a mean DP of 95 (61\% conversion, CTA efficiency $=96 \%$ ). DMF GPC analysis indicated an $M_{\mathrm{n}}$ of $13800 \mathrm{~g} \mathrm{~mol}^{-1}$ and a $M_{\mathrm{w}} / M_{\mathrm{n}}$ of 1.21 .

This PNAEP $_{95}$ macro-CTA was subsequently utilized for the RAFT aqueous solution polymerization of NIPAM, targeting PNIPAM DPs between 100 and 300 and using a PNAEP ${ }_{95} /$ KPS molar ratio of 5.0 (see Scheme 3). The RAFT polymerization of NIPAM was conducted in an oil bath set to $22{ }^{\circ} \mathrm{C}$, which is below the LCST of PNIPAM homopolymer. $^{41-44}$ NIPAM conversions of at least $99 \%$ were achieved for all PNAEP $_{95}-$ PNIPAM $_{x}$ diblock copolymers 
Scheme 3. Synthesis of a Series of PNAEP $_{95}-$ PNIPAM $_{x}$ Diblock Copolymers by RAFT Aqueous Solution Polymerization of NIPAM at $22{ }^{\circ} \mathrm{C}$ Using a PNAEP $_{95}$ Precursor $^{a}$

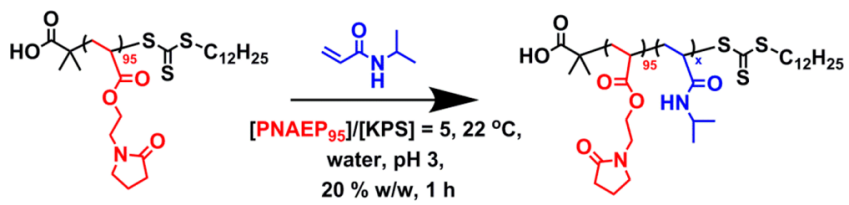

${ }^{a} \mathrm{~A}$ low-temperature redox initiator $(\mathrm{KPS} / \mathrm{AsAc}$ molar ratio $=1.0)$ was utilized, and the macro-CTA/initiator molar ratio was 5.0.

within $1 \mathrm{~h}$ at this temperature, as judged by ${ }^{1} \mathrm{H}$ NMR studies conducted in $\mathrm{D}_{2} \mathrm{O}$. DMF GPC analysis of this series of PNAEP $_{95}-$ PNIPAM $_{x}$ diblock copolymers indicated a monotonic increase in $M_{\mathrm{n}}$ with increasing PNIPAM DP. Relatively low dispersities $\left(M_{\mathrm{w}} / M_{\mathrm{n}}<1.40\right)$ were observed in all cases, indicating reasonably good RAFT control. Moreover, comparison of the GPC traces obtained for these PNAEP $_{95}-$ $\operatorname{PNIPAM}_{x}$ diblock copolymers with that of the precursor PNAEP $_{95}$ macro-CTA indicated relatively high blocking efficiencies (Figure 7).

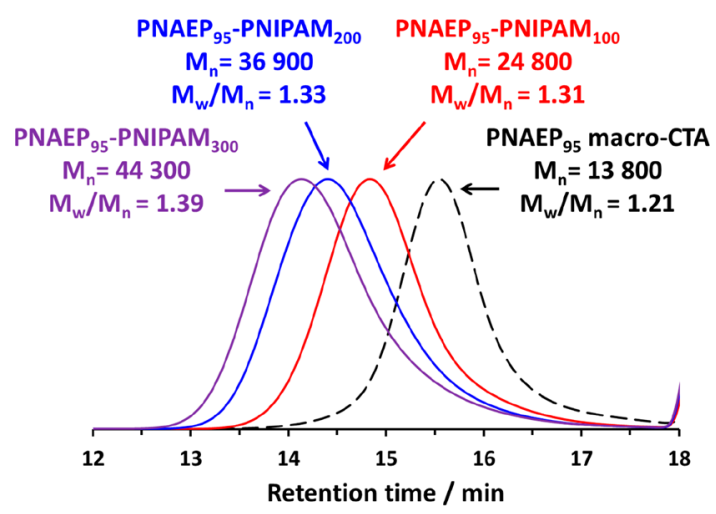

Figure 7. DMF GPC curves obtained for a series of three PNAEP $_{95}-$ PNIPAM $_{x}$ diblock copolymers and the corresponding PNAEP 95 macro-CTA (dashed trace). The NIPAM conversion was more than $99 \%$ for each of the three diblock copolymers.

PNIPAM is a well-known thermoresponsive polymer that exhibits LCST behavior in aqueous solution at around 32 ${ }^{\circ} \mathrm{C} .{ }^{41-44}$ Thus, proton signals assigned to the PNAEP and PNIPAM blocks are observed when inspecting a ${ }^{1} \mathrm{H}$ NMR spectrum recorded for the PNAEP $_{95}-$ PNIPAM $_{200}$ diblock copolymer in $\mathrm{D}_{2} \mathrm{O}$ at $20{ }^{\circ} \mathrm{C}$ (see Figure 8a). However, on heating this copolymer solution up to $50{ }^{\circ} \mathrm{C}$, the PNIPAM chains become substantially desolvated. This leads to attenuation of all the PNIPAM signals (Figure $8 \mathrm{~b}$ ). On the other hand, all the PNAEP signals remain well-solvated under these conditions. Variable temperature ${ }^{1} \mathrm{H}$ NMR studies indicated that the two methyl signals assigned to the pendent isopropyl group of PNIPAM (labeled $\mathrm{d}^{\prime}$ in Figure 8) become substantially attenuated between 34 and $36{ }^{\circ} \mathrm{C}$ (Figure 8c), suggesting reduced chain mobility owing to dehydration. These spectral changes are consistent with in situ self-assembly of the diblock copolymer chains to form PNIPAM-core micelles.

Dynamic light scattering (DLS) was utilized to gain further evidence for such micellar self-assembly. A $0.10 \% \mathrm{w} / \mathrm{w}$
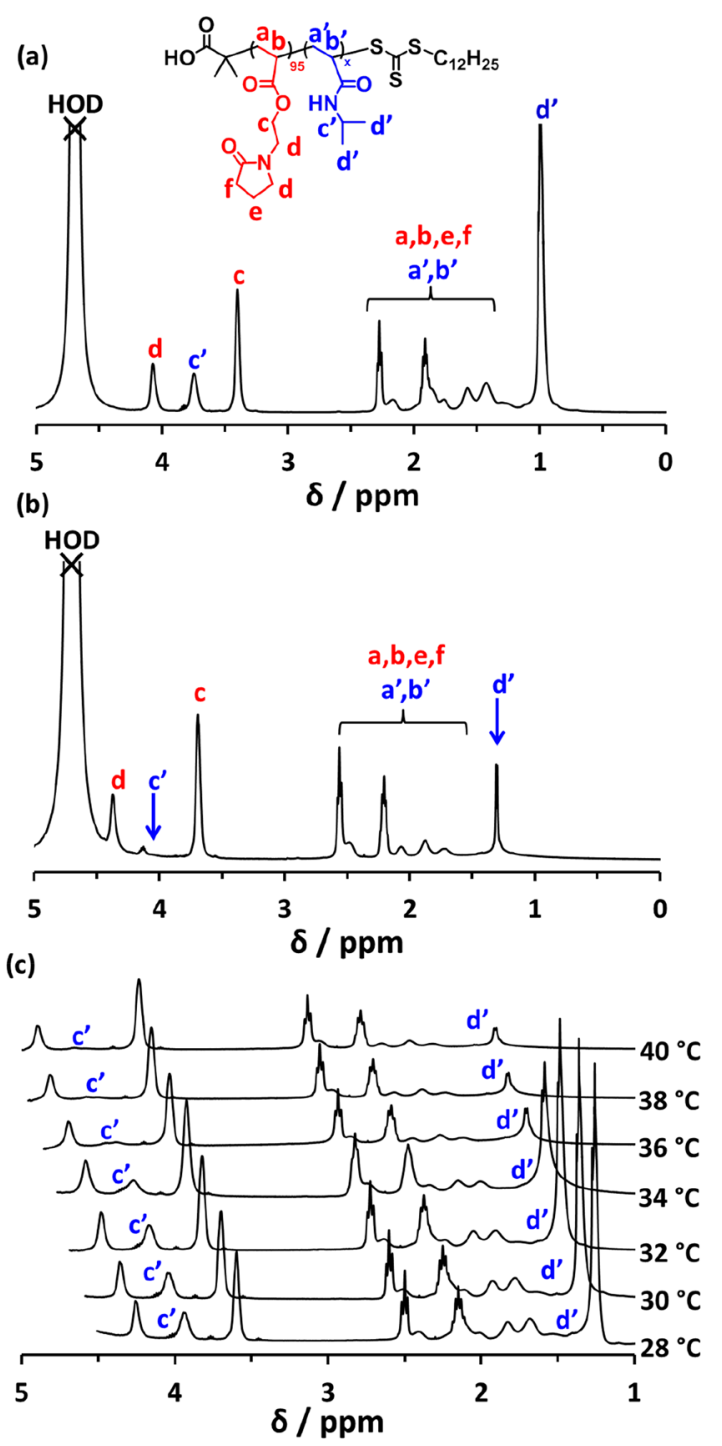

Figure 8. ${ }^{1} \mathrm{H}$ NMR spectra recorded for a PNAEP $_{95}-$ PNIPAM $_{200}$ diblock copolymer in $\mathrm{D}_{2} \mathrm{O}$ at (a) $20{ }^{\circ} \mathrm{C}$ (upper spectrum), (b) $50{ }^{\circ} \mathrm{C}$ (middle spectrum), and (c) between 28 and $40{ }^{\circ} \mathrm{C}$

PNAEP $_{95}-$ PNIPAM $_{200}$ solution was monitored between 25 and $50{ }^{\circ} \mathrm{C}$. The weak light scattering and relatively small hydrodynamic diameter observed at $25{ }^{\circ} \mathrm{C}$ indicated that this copolymer existed as molecularly dissolved chains at this temperature (see Figure 9). On heating this copolymer solution, relatively large, ill-defined aggregates are obtained at around $35^{\circ} \mathrm{C}$, before well-defined near-monodisperse spherical nanoparticles $(z$-average diameter $=51 \mathrm{~nm}$; PDI $=0.006)$ are formed above $\sim 40{ }^{\circ} \mathrm{C}$, in good agreement with the variable temperature ${ }^{1} \mathrm{H}$ NMR spectra shown in Figure $8 \mathrm{c}$. Similar examples of so-called anomalous micellization have been reported in the literature. ${ }^{44-47}$ In at least some cases, such observations have been attributed to homopolymer contamination by the more hydrophobic block. ${ }^{44}$ At first sight, this hypothesis does not seem to be applicable in the present case because the PNAEP precursor block is more hydrophilic than the PNIPAM block. However, in principle, the RAFT mechanism can generate a low level of PNIPAM homopolymer impurity, ${ }^{48}$ so this possible explanation cannot be excluded.

RAFT Aqueous Solution Polymerization of NAEP at $30{ }^{\circ} \mathrm{C}$ Using a PDEA 99 Macro-CTA. A PDEA macro-CTA 


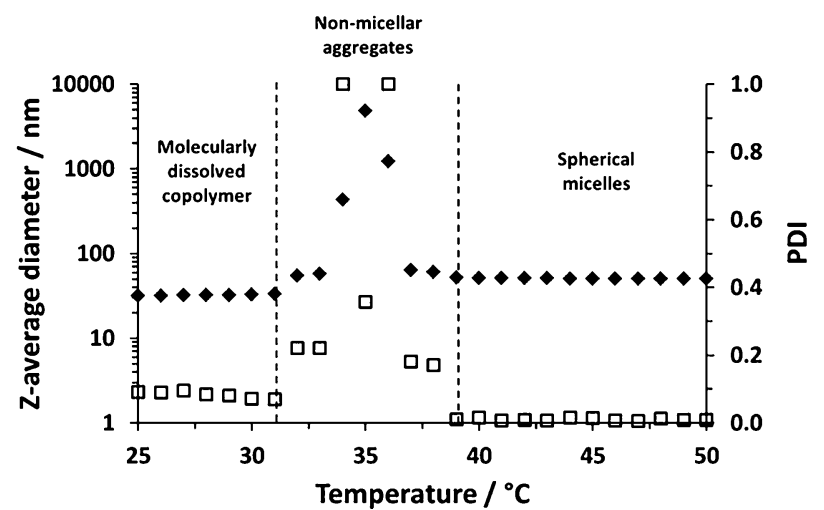

Figure 9. Variable temperature DLS studies of a $0.10 \% \mathrm{w} / \mathrm{w}$ aqueous solution of a $\mathrm{PNAEP}_{95}-\mathrm{PNIPAM}_{200}$ diblock copolymer at $\mathrm{pH} 3$. Molecularly dissolved copolymer chains are obtained at $25{ }^{\circ} \mathrm{C}$, anomalous micellization occurs at around $35{ }^{\circ} \mathrm{C}$, and well-defined, near-monodisperse micelles are formed above $40{ }^{\circ} \mathrm{C}$. Such selfassembly is driven by the well-known thermoresponsive nature of the PNIPAM block, which exhibits inverse temperature solubility behavior.

(target $\mathrm{DP}=100)$ was prepared via RAFT solution polymerization of DEA in THF at $70{ }^{\circ} \mathrm{C}$ using MPETTC (see Scheme 4a). This precursor was purified via successive precipitation into a 10 -fold excess of alkaline aqueous solution ( $\mathrm{pH} 10)$ to afford a yellow gum, which was dried under vacuum before being dissolved in its protonated form using 1.0 $\mathrm{M}$ aqueous $\mathrm{HCl}$. The resulting PDEA hydrochloride salt was isolated via precipitation into a 10 -fold excess of acetone to yield a yellow powder. ${ }^{1} \mathrm{H}$ NMR studies indicated negligible residual monomer $(<1 \%)$, while end-group analysis based on the aromatic proton signals assigned to the MPETTC RAFT chain-ends indicated a mean DP of 99. Chloroform GPC analysis indicated a monomodal trace with an $M_{\mathrm{n}}$ of $10800 \mathrm{~g}$ $\mathrm{mol}^{-1}$ and an $M_{\mathrm{w}} / M_{\mathrm{n}}$ of 1.24 (see Table S1).

This PDEA $_{99}$ macro-CTA was then utilized for the RAFT aqueous solution polymerization of NAEP targeting a PNAEP DP of 50 to 100, as depicted in Scheme 4b. These syntheses were conducted in acidic aqueous solution to ensure that both blocks were fully water-soluble (with the protonated PDEA block being present in its cationic polyelectrolyte form). ${ }^{1} \mathrm{H}$ NMR studies confirmed that high NAEP conversions (>99\%) were achieved in each case. Inspecting Table S1, DMF GPC analysis of this series of $\mathrm{PDEA}_{99}-\mathrm{PNAEP}_{y}$ diblock copolymers confirms that higher $M_{\mathrm{n}}$ values are obtained on increasing the target PNAEP DP from 50 to 100 . A relatively low dispersity $\left(M_{\mathrm{w}} / M_{\mathrm{n}}<1.30\right)$ was observed for each PDEA $_{100}-$ PNAEP $_{y}$ diblock copolymer, as expected.

${ }^{1} \mathrm{H}$ NMR studies were conducted on a $\mathrm{PDEA}_{99}-\mathrm{PNAEP}_{75}$ diblock copolymer in acidic aqueous solution $(0.001 \mathrm{M} \mathrm{DCl}$ in $\mathrm{D}_{2} \mathrm{O}$, or $\mathrm{pH} 3$ ). Under such conditions, all the tertiary amine groups in the PDEA block are protonated, and hence both blocks are fully solvated. Thus, all the expected ${ }^{1} \mathrm{H}$ NMR signals for both blocks are visible under such conditions (see Figure 10a). In particular, the six pendent methyl protons associated with the PDEA block are prominent between 1.20 and $1.50 \mathrm{ppm}$. On addition of sufficient $\mathrm{NaOD}$, the $\mathrm{PDEA}_{x}$ block becomes completely deprotonated $\left(\mathrm{p} K_{\mathrm{a}} \sim 7.3\right)$ and hence hydrophobic. ${ }^{49}$ This drives in situ self-assembly to form PDEA-core micelles with the PNAEP chains acting as the stabilizer block. Accordingly, the ${ }^{1} \mathrm{H}$ NMR signals associated with the desolvated PDEA block are no longer visible (Figure

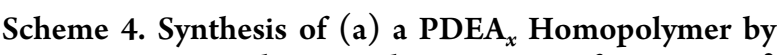
RAFT Aqueous Solution Polymerization of DEA at $70^{\circ} \mathrm{C}$ in THF Using a Morpholine-Functional RAFT CTA; (b) Protonation of the PDEA 100 Homopolymer Precursor Using 1.0 M HCl; (c) Synthesis of PDEA $100-$ PNAEP $_{y}$ Diblock Copolymers by RAFT Aqueous Solution Polymerization of NAEP at $30^{\circ} \mathrm{C}$ Using a Protonated Water-Soluble PDEA Precursor and a Macro-CTA/Initiator Molar Ratio of 5.0 $($ KPS/AsAc Molar Ratio = 1.0)

(a)<smiles>CC(C)(CC(=O)NCCN1CCOCC1)SC(=S)SCCc1ccccc1</smiles>

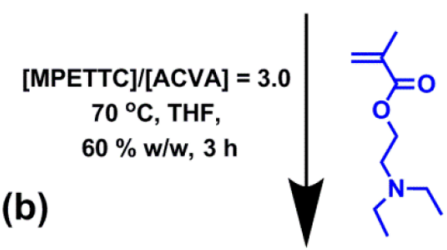<smiles>CCN(CC)CCOC(=O)C(C)(C)CC(C)(C)CC(C)(C)CCC(=O)NCCN1CCOCC1</smiles><smiles>CCC(C)[CH][N+]1(CCNC(=O)CCC(C)(C)C[C@](C)(SC(=S)SCCc2ccccc2)C(=O)OCC[NH+](CC)CC)CCOCC1</smiles><smiles>C=CC(=O)OCCN1CCCC1=O</smiles><smiles>CC[NH+](CC)CCOC(=O)[C@](C)(CC(C)(C)CC(C)(C)SC(=S)SCCc1ccccc1)C(=O)OCCN1CCCC1=O</smiles>

$10 \mathrm{~b})$. The $z$-average micelle diameter is reduced from 100 to $40 \mathrm{~nm}$ for four PDEA $_{100}-\mathrm{PNAEP}_{y}$ diblock copolymers as the DP $(y)$ of the PNAEP block is increased from 50 to 100 (see Figure 11). This indicates lower micelle aggregation numbers when using longer stabilizer blocks, which is consistent with well-known theories of micellization reported in the literature. ${ }^{50,51}$ 


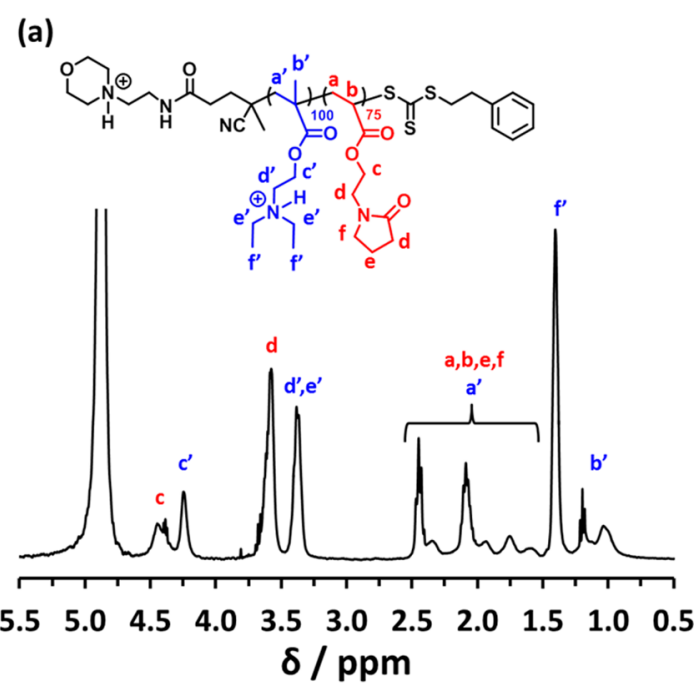

(b)

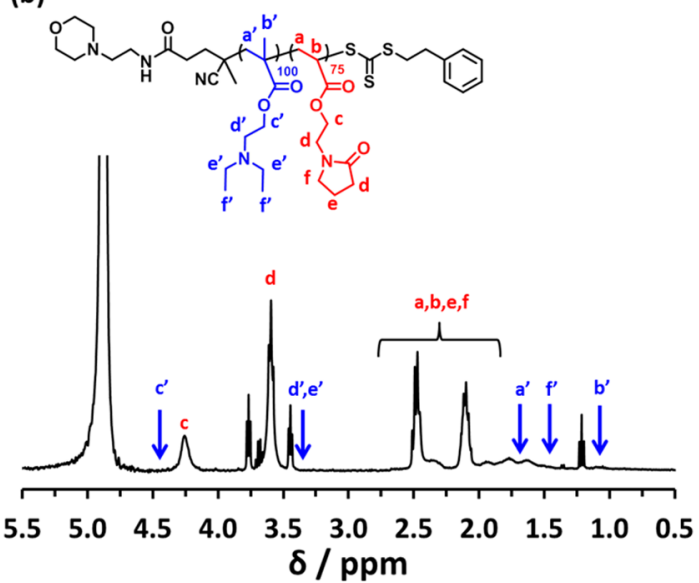

Figure 10. ${ }^{1} \mathrm{H}$ NMR spectra recorded for a $\mathrm{PDEA}_{99}-\mathrm{PNAEP}_{75}$ diblock copolymer at $25{ }^{\circ} \mathrm{C}$ : (a) in $\mathrm{DCl} / \mathrm{D}_{2} \mathrm{O}$ at $\mathrm{pH} 3$ (upper spectrum) and (b) in $\mathrm{NaOD} / \mathrm{D}_{2} \mathrm{O}$ at $\mathrm{pH} 10$ (lower spectrum).

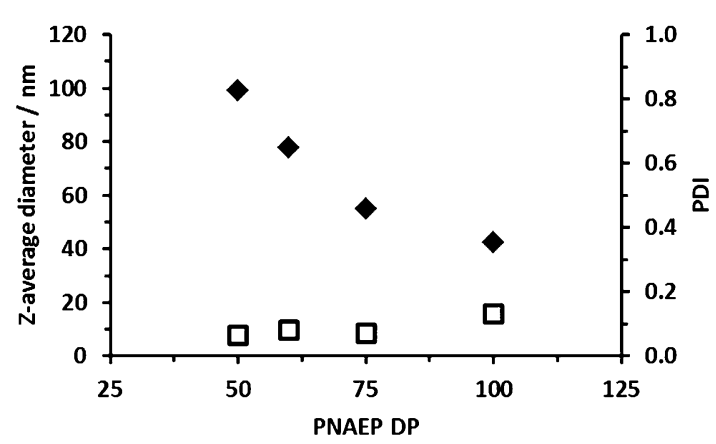

Figure 11. DLS studies for four $\mathrm{PDEA}_{100}-\mathrm{PNAEP}_{y}$ diblock copolymers (where $y=50-100$ ) in dilute aqueous solution at $\mathrm{pH} 10$.

\section{CONCLUSIONS}

A trithiocarbonate-based CTA (DDMAT) was used for the RAFT aqueous solution polymerization of 2-( $N$-acryloyloxy)ethylpyrrolidone (NAEP) to prepare a series of $\mathrm{PNAEP}_{x}$ homopolymers with mean degrees of polymerization varying from 40 to 400 . Substituting a typical azo initiator for a lowtemperature redox initiator enabled the reaction temperature to be lowered from 70 to $30{ }^{\circ} \mathrm{C}$ while also reducing the reaction time from 60 to $5 \mathrm{~min}$. GPC analyses indicated wellcontrolled RAFT syntheses under these conditions $\left(M_{\mathrm{w}} / M_{\mathrm{n}} \sim\right.$ $1.20)$. Unlike the poly(2-(N-methacryloyloxy)ethylpyrrolidone) homopolymers reported previously, these PNAEP $_{x}$ homopolymers do not possess LCST behavior as judged by turbidimetry studies, which indicates that they are significantly more hydrophilic. High monomer conversions ( $\geq 99 \%$ ) were achieved when targeting mean DPs between 40 and 400 at $60 \% \mathrm{w} / \mathrm{w}$ NAEP. DSC analysis indicated that PNAEP homopolymers with DPs of up to 400 exhibited glass transition temperatures below ambient temperature.

Using such trithiocarbonate-terminated PNAEP homopolymers as precursors, two series of PNAEP $_{62}-$ PHEA $_{x}$ and PNAEP $_{71}-$ POEGA $_{x}$ diblock copolymers were prepared via RAFT aqueous solution polymerization of either HEA or OEGA, respectively. High monomer conversions ( $\geq 99 \%)$ were achieved when targeting mean DPs between 50 and 400. DMF GPC analysis confirmed that relatively low dispersities $\left(M_{\mathrm{w}} /\right.$ $M_{\mathrm{n}} \leq 1.35$ ) and high blocking efficiencies were obtained for these two all-acrylic formulations, with monomodal GPC traces suggesting reasonably good RAFT control.

Two new classes of stimulus-responsive PNAEP-based diblock copolymers were also prepared. Thus, a series of thermoresponsive PNAEP $_{95}-$ PNIPAM $_{x}$ diblock copolymers were prepared via RAFT aqueous solution polymerization of NIPAM at $22{ }^{\circ} \mathrm{C}$, which is below the LCST of the PNIPAM block. Variable temperature DLS studies indicated the presence of relatively large, non-micellar aggregates between 32 and $39{ }^{\circ} \mathrm{C}$ prior to the formation of well-defined PNIPAMcore spherical micelles above $42{ }^{\circ} \mathrm{C}(51 \mathrm{~nm}$; PDI $=0.006)$. Variable temperature ${ }^{1} \mathrm{H}$ NMR studies indicated that such selfassembly was accompanied by substantial desolvation of the PNIPAM block, as expected. Finally, a PDEA 100 macro-CTA was chain-extended via RAFT aqueous solution polymerization of NAEP at $30{ }^{\circ} \mathrm{C}$. ${ }^{1} \mathrm{H}$ NMR studies confirmed that high conversions $(\geq 99 \%)$ were achieved when targeting mean DPs of 50-100 and GPC studies indicated good RAFT control and low final dispersities $\left(M_{\mathrm{w}} / M_{\mathrm{n}} \leq 1.30\right)$ in each case. Such $\mathrm{PDEA}_{99}-\mathrm{PNAEP}_{y}$ diblock copolymers exhibited $\mathrm{pH}$-responsive behavior in aqueous solution. Molecular dissolution occurred at low $\mathrm{pH}$, but spherical micelles comprising deprotonated PDEA cores were obtained at $\mathrm{pH}$ 10. DLS studies indicated that increasing the PNAEP DP led to a significant reduction in the $z$-average diameter for this series of $\mathrm{PDEA}_{99}-\mathrm{PNAEP}_{x}$ diblock copolymers.

\section{ASSOCIATED CONTENT}

Supporting Information

The Supporting Information is available free of charge on the ACS Publications website at DOI: 10.1021/acs.macromol.8b01627.

Figures S1 and S2; Table S1 (PDF)

\section{AUTHOR INFORMATION}

\section{Corresponding Author}

*E-mail s.p.armes@shef.ac.uk (S.P.A.).

ORCID

S. P. Armes: 0000-0002-8289-6351

\section{Notes}

The authors declare the following competing financial interest(s): A patent application has been filed to protect the results reported in this manuscript. 


\section{ACKNOWLEDGMENTS}

EPSRC is thanked for funding a CDT PhD studentship for the first author (EP/L016281). Ashland Specialty Ingredients (Bridgewater, $\mathrm{NJ}$ ) is thanked for financial support of this $\mathrm{PhD}$ project, for supplying the NMEP and NAEP monomers, and for permission to publish this work. S.P.A. also thanks the ERC for a five-year Advanced Investigator grant (PISA 320372) and the EPSRC for an Established Career Particle Technology Fellowship (EP/R003009). Dr. N. J. W. Penfold is thanked for the MPETTC synthesis and GPC protocol determination, and Harry Wright is acknowledged for his assistance in measuring the polymerization exotherms.

\section{REFERENCES}

(1) Haaf, F.; Sanner, A.; Straub, F. Polymers of N-Vinylpyrrolidone: Synthesis, Characterization and Uses. Polym. J. 1985, 17, 143.

(2) Teodorescu, M.; Bercea, M. Poly(vinylpyrrolidone) - A Versatile Polymer for Biomedical and Beyond Medical Applications. Polym.-Plast. Technol. Eng. 2015, 54, 923-943.

(3) Lee, C. M.; Kumler, W. D. The Dipole Moment and Structure of Five- and Six-membered Lactams. J. Am. Chem. Soc. 1961, 83, 45934596.

(4) Einaga, H.; Harada, M. Photochemical Preparation of Poly(Nvinyl-2-pyrrolidone)-Stabilized Platinum Colloids and Their Deposition on Titanium Dioxide. Langmuir 2005, 21, 2578-2584.

(5) Tsunoyama, H.; Sakurai, H.; Negishi, Y.; Tsukuda, T. SizeSpecific Catalytic Activity of Polymer-Stabilized Gold Nanoclusters for Aerobic Alcohol Oxidation in Water. J. Am. Chem. Soc. 2005, 127, 9374-9375.

(6) Jiang, J.; Zhu, L.; Zhu, L.; Zhang, H.; Zhu, B.; Xu, Y. Antifouling and Antimicrobial Polymer Membranes Based on Bioinspired Polydopamine and Strong Hydrogen-Bonded Poly(N-vinyl pyrrolidone). ACS Appl. Mater. Interfaces 2013, 5, 12895-12904.

(7) Faragalla, M. M.; Hill, D. J. T.; Whittaker, A. K. The copolymerization of $\mathrm{N}$-vinyl-2-pyrrolidone with 2-hydroxyethyl methacrylate. Polym. Bull. 2002, 47, 421-427.

(8) Hosaka, S.; Yamada, A.; Tanzawa, H.; Momose, T.; Magatani, H.; Nakajima, A. Mechanical properties of the soft contact lens of poly(methyl methacrylate-N-vinylpyrrolidone). J. Biomed. Mater. Res. 1980, 14, 557-566.

(9) Carli, F.; Garbassi, F. Characterization of drug loading in crospovidone by x-ray photoelectron spectroscopy. J. Pharm. Sci. 1985, 74, 963-967.

(10) Arshady, R. Suspension, emulsion, and dispersion polymerization: A methodological survey. Colloid Polym. Sci. 1992, 270, $717-$ 732.

(11) Prosapio, V.; Reverchon, E.; De Marco, I. Coprecipitation of Polyvinylpyrrolidone/ $\beta$-Carotene by Supercritical Antisolvent Processing. Ind. Eng. Chem. Res. 2015, 54, 11568-11575.

(12) Stejskal, J.; Kratochvíl, P.; Helmstedt, M. Polyaniline Dispersions. 5. Poly(vinyl alcohol) and Poly(N-vinylpyrrolidone) as Steric Stabilizers. Langmuir 1996, 12, 3389-3392.

(13) Davis, T. P.; Huglin, M. B. Effect of composition on properties of copolymeric N-vinyl-2-pyrrolidonemethyl methacrylate hydrogels and organogels. Polymer 1990, 31, 513-519.

(14) Moad, G.; Rizzardo, E.; Thang, S. H. Living Radical Polymerization by the RAFT ProcessA First Update. Aust. J. Chem. 2006, 59, 669-692.

(15) Moad, G.; Rizzardo, E.; Thang, S. H. Living Radical Polymerization by the RAFT Process A Second Update. Aust. J. Chem. 2009, 62, 1402-1472.

(16) Devasia, R.; Bindu, R. L.; Borsali, R.; Mougin, N.; Gnanou, Y. Controlled Radical Polymerization of N-Vinylpyrrolidone by Reversible Addition-Fragmentation Chain Transfer Process. Macromol. Symp. 2005, 229, 8-17.

(17) Reader, P. W.; Pfukwa, R.; Jokonya, S.; Arnott, G. E.; Klumperman, B. Synthesis of $\alpha, \omega$-heterotelechelic PVP for bio- conjugation, via a one-pot orthogonal end-group modification procedure. Polym. Chem. 2016, 7, 6450-6456.

(18) Giliomee, J.; Pfukwa, R.; Gule, N. P.; Klumperman, B. Smart block copolymers of PVP and an alkylated PVP derivative: synthesis, characterization, thermoresponsive behaviour and self-assembly. Polym. Chem. 2016, 7, 1138-1146.

(19) Pound, G.; Eksteen, Z.; Pfukwa, R.; McKenzie, J. M.; Lange, R. F. M.; Klumperman, B. Unexpected reactions associated with the xanthate-mediated polymerization of N-vinylpyrrolidone. J. Polym. Sci., Part A: Polym. Chem. 2008, 46, 6575-6593.

(20) Pound, G.; McKenzie, J. M.; Lange, R. F. M.; Klumperman, B. Polymer-protein conjugates from [small omega]-aldehyde endfunctional poly $(\mathrm{N}$-vinylpyrrolidone) synthesised via xanthate-mediated living radical polymerisation. Chem. Commun. 2008, 3193-3195.

(21) Keddie, D. J. A guide to the synthesis of block copolymers using reversible-addition fragmentation chain transfer (RAFT) polymerization. Chem. Soc. Rev. 2014, 43, 496-505.

(22) Stace, S. J.; Moad, G.; Fellows, C. M.; Keddie, D. J. The effect of Z-group modification on the RAFT polymerization of $\mathrm{N}$ vinylpyrrolidone controlled by "switchable" N-pyridyl-functional dithiocarbamates. Polym. Chem. 2015, 6, 7119-7126.

(23) Bilalis, P.; Pitsikalis, M.; Hadjichristidis, N. Controlled nitroxide-mediated and reversible addition-fragmentation chain transfer polymerization of $\mathrm{N}$-vinylpyrrolidone: Synthesis of block copolymers with styrene and 2-vinylpyridine. J. Polym. Sci., Part A: Polym. Chem. 2006, 44, 659-665.

(24) Johnson, I. J.; Khosravi, E.; Musa, O. M.; Simnett, R. E.; Eissa, A. M. Xanthates designed for the preparation of N-Vinyl pyrrolidonebased linear and star architectures via RAFT polymerization. J. Polym. Sci., Part A: Polym. Chem. 2015, 53, 775-786.

(25) McCormick, C. L.; Lowe, A. B. Aqueous RAFT Polymerization: Recent Developments in Synthesis of Functional WaterSoluble (Co)polymers with Controlled Structures. Acc. Chem. Res. 2004, 37, 312-325.

(26) Guinaudeau, A.; Coutelier, O.; Sandeau, A.; Mazières, S.; Nguyen Thi, H. D.; Le Drogo, V.; Wilson, D. J.; Destarac, M. Facile Access to Poly(N-vinylpyrrolidone)-Based Double Hydrophilic Block Copolymers by Aqueous Ambient RAFT/MADIX Polymerization. Macromolecules 2014, 47, 41-50.

(27) Guinaudeau, A.; Mazieres, S.; Wilson, D. J.; Destarac, M. Aqueous RAFT/MADIX polymerisation of $\mathrm{N}$-vinyl pyrrolidone at ambient temperature. Polym. Chem. 2012, 3, 81-84.

(28) Cunningham, V. J.; Ning, Y.; Armes, S. P.; Musa, O. M. Poly(N-2-(methacryloyloxy)ethyl pyrrolidone)-poly(benzyl methacrylate) diblock copolymer nano-objects via RAFT alcoholic dispersion polymerisation in ethanol. Polymer 2016, 106, 189-199.

(29) Cunningham, V. J.; Derry, M. J.; Fielding, L. A.; Musa, O. M.; Armes, S. P. RAFT Aqueous Dispersion Polymerization of N-(2(Methacryloyloxy)ethyl)pyrrolidone: A Convenient Low Viscosity Route to High Molecular Weight Water-Soluble Copolymers. Macromolecules 2016, 49, 4520-4533.

(30) Cunningham, V. J.; Armes, S. P.; Musa, O. M. Synthesis, characterisation and Pickering emulsifier performance of poly(stearyl methacrylate)-poly(N-2-(methacryloyloxy)ethyl pyrrolidone) diblock copolymer nano-objects via RAFT dispersion polymerisation in $\mathrm{n}$ dodecane. Polym. Chem. 2016, 7, 1882-1891.

(31) Iskander, G. M.; Baker, L. E.; Wiley, D. E.; Davis, T. P. Synthesis and polymerization of new pyrrolidone-containing methacrylate monomers. Polymer 1998, 39, 4165-4169.

(32) Deng, J.; Shi, Y.; Jiang, W.; Peng, Y.; Lu, L.; Cai, Y. Facile Synthesis and Thermoresponsive Behaviors of a Well-Defined Pyrrolidone Based Hydrophilic Polymer. Macromolecules 2008, 41, 3007-3014.

(33) Shi, Y.; Liu, G.; Gao, H.; Lu, L.; Cai, Y. Effect of Mild Visible Light on Rapid Aqueous RAFT Polymerization of Water-Soluble Acrylic Monomers at Ambient Temperature: Initiation and Activation. Macromolecules 2009, 42, 3917-3926.

(34) Jones, E. R.; Semsarilar, M.; Blanazs, A.; Armes, S. P. Efficient Synthesis of Amine-Functional Diblock Copolymer Nanoparticles via 
RAFT Dispersion Polymerization of Benzyl Methacrylate in Alcoholic Media. Macromolecules 2012, 45, 5091-5098.

(35) Penfold, N. J. W.; Lovett, J. R.; Warren, N. J.; Verstraete, P.; Smets, J.; Armes, S. P. pH-Responsive non-ionic diblock copolymers: protonation of a morpholine end-group induces an order-order transition. Polym. Chem. 2016, 7, 79-88.

(36) Junkers, T.; Koo, S. P. S.; Davis, T. P.; Stenzel, M. H.; BarnerKowollik, C. Mapping Poly(butyl acrylate) Product Distributions by Mass Spectrometry in a Wide Temperature Range: Suppression of Midchain Radical Side Reactions. Macromolecules 2007, 40, 89068912.

(37) Heatley, F.; Lovell, P. A.; Yamashita, T. Chain Transfer to Polymer in Free-Radical Solution Polymerization of 2-Ethylhexyl Acrylate Studied by NMR Spectroscopy. Macromolecules 2001, 34, 7636-7641.

(38) Misra, G. S.; Bajpai, U. D. N. Redox polymerization. Prog. Polym. Sci. 1982, 8, 61-131.

(39) Sun, J.; Peng, Y.; Chen, Y.; Liu, Y.; Deng, J.; Lu, L.; Cai, Y. Effect of Molecular Structure on Thermoresponsive Behaviors of Pyrrolidone-Based Water-Soluble Polymers. Macromolecules 2010, 43, 4041-4049.

(40) Boyer, R. F. The Relation of Transition Temperatures to Chemical Structure in High Polymers. Rubber Chem. Technol. 1963, $36,1303-1421$.

(41) Saunders, B. R.; Vincent, B. Microgel particles as model colloids: theory, properties and applications. Adv. Colloid Interface Sci. 1999, 80, 1-25.

(42) Hu, L.; Sarker, A. K.; Islam, M. R.; Li, X.; Lu, Z.; Serpe, M. J. Poly (N-isopropylacrylamide) microgel-based assemblies. J. Polym. Sci., Part A: Polym. Chem. 2013, 51, 3004-3020.

(43) Heskins, M.; Guillet, J. E. Solution Properties of Poly(Nisopropylacrylamide). J. Macromol. Sci., Chem. 1968, 2, 1441-1455.

(44) Lodge, T. P.; Bang, J.; Hanley, K. J.; Krocak, J.; Dahlquist, S.; Sujan, B.; Ott, J. Origins of Anomalous Micellization in Diblock Copolymer Solutions. Langmuir 2003, 19, 2103-2109.

(45) Fukumine, Y.; Inomata, K.; Takano, A.; Nose, T. Micellization behavior of diblock copolymers in solution near the critical micelle temperature. Polymer 2000, 41, 5367-5374.

(46) Tuzar, Z.; Sikora, A.; Petrus, V.; Kratochvíl, P. Anomalous behaviour of solutions of styrene-butadiene block copolymers in some solvents. Makromol. Chem. 1977, 178, 2743-2746.

(47) Zhou, Z.; Chu, B. Anomalous association behavior of an ethylene oxide/propylene oxide $\mathrm{ABA}$ block copolymer in water. Macromolecules 1987, 20, 3089-3091.

(48) Moad, G.; Rizzardo, E.; Thang, S. H. Radical additionfragmentation chemistry in polymer synthesis. Polymer 2008, 49, $1079-1131$.

(49) Bütün, V.; Armes, S. P.; Billingham, N. C. Synthesis and aqueous solution properties of near-monodisperse tertiary amine methacrylate homopolymers and diblock copolymers. Polymer 2001, 42, 5993-6008.

(50) Canning, S. L.; Neal, T. J.; Armes, S. P. pH-Responsive Schizophrenic Diblock Copolymers Prepared by PolymerizationInduced Self-Assembly. Macromolecules 2017, 50, 6108-6116.

(51) Moad, G. RAFT polymerization to form stimuli-responsive polymers. Polym. Chem. 2017, 8, 177-219. 